\title{
The Dynamics of UK and US Inflation Expectations*
}

\author{
Deborah Gefang \\ Department of Economics \\ University of Lancaster \\ email: d.gefang@lancaster.ac.uk \\ Gary Koop \\ Department of Economics \\ University of Strathclyde \\ email: Gary.Koop@strath.ac.uk \\ Simon M. Potter \\ Macroeconomics and Monetary Studies Function \\ Federal Reserve Bank of New York \\ email: simon.potter@ny.frb.org
}

December 2008

\begin{abstract}
This paper investigates the relationship between short term and long term inflation expectations in the US and the UK with a focus on inflation pass through (i.e. how changes in short term expectations affect long term expectations). An econometric methodology is used which allows us to uncover the relationship between inflation pass through and various explanatory variables. We relate our empirical results to theoretical models of anchored, contained and unmoored inflation expectations. For neither country do we find anchored or unmoored inflation expectations. For the US, contained inflation expectations are found. For the UK, our findings are not consistent with the specific model of contained inflation expectations presented here, but are consistent with a more broad view of expectations being constrained by the existence of an inflation target.
\end{abstract}

*The views expressed in this paper are those of the authors and do not necessarily reflect the views of the Federal Reserve Bank of New York or the Federal Reserve System. Gary Koop is a Fellow of the Rimini Center for Economic Analysis. 


\section{Introduction}

Knowledge of how agents form inflation expectations is necessary for central bankers and economic theorists alike. In the UK, the Bank of England has an official inflation target. ${ }^{1}$ The decision to adopt such a target was motivated partly by the desire to fix inflation expectations (at least in the long run). But, it is possible that agents will not believe that the target is credible or, even if it has some credibility, that the target only tends to weakly pull inflation expectations towards it. Arguments such as those presented in Gurkaynak, Levin and Swanson (2006) imply that if the inflation target is believed, then long term inflation expectations should be drawn to this target. Although the US has no official target, the Federal Open Market Committee (FOMC) does have a mandate for price stability along with other goals such as maximum sustainable output growth and moderate long term interest rates. The existence of this mandate suggests that US inflation expectations might be constrained in some manner.

Are inflation expectations always anchored? If not, are they contained? Or are they umoored? Are there differences between the UK, with its official target for inflation, and the US which has no such explicit target? These are questions of great policy relevance that we try and address in this paper. We do this by using data on short-term and long-term expected inflation derived from real and nominal U.K. and U.S. government bonds. Our particular focus is on inflation pass through: how changes in short-term inflation expectations influence long-term expectations. We begin by discussing various models of inflation expectations and describe their implications for a key parameter which we call the inflation pass through coefficient. Then we describe our econometric methodology which uses the smoothly mixing regression approach of Geweke and Keane (2007). The advantage of this approach is its extreme flexibility in modelling the inflation pass through coefficient. It allows us, in a data based fashion, to investigate whether this coefficient is constant, or varies over time, or depends on the level of inflation, or depends on how far inflation is from target, etc. We then tie our empirical findings with our theoretical models of inflation expectations to see if any of them receive support from the data. For the US, we find support for a model of contained inflation expectations. For the UK, empirical results

\footnotetext{
${ }^{1}$ Until 9 December, 2003 the target was $2.5 \%$ (at an annual rate measured using the retail price index, RPI). After this date, the inflation target was $2 \%$ (measured using the consumer price index, CPI, which has historically been roughly $0.5 \%$ below the RPI).
} 
are not completely consistent with any of our theoretical models of inflation expectations. However, we present strong evidence against either unmoored or anchored inflation expectations. UK results are most close to those suggested by our model of contained inflation expectations and clearly suggest that inflation expectations are constrained in some manner in the UK.

\section{Theoretical Models of Inflation Expecta- tions}

In this section, following Potter and Rosenberg (2007), we briefly describe various popular models of inflation expectations (anchored, contained and unmoored inflation expectations) and discuss their implications for the inflation pass through coefficient. Before doing so, we must define what we mean by the inflation pass through coefficient. Consider the simple regression model:

$$
\Delta y_{t}=\beta \Delta x_{t}+\varepsilon_{t},
$$

where $y_{t}$ is a measure of long term inflation expectations at time $\mathrm{t}$ and $x_{t}$ are short term inflation expectations. $\beta$ measures the impact of changes in short term expectations on long term expectations and is called the inflation pass through coefficient. If the Bank of England's inflation target is $\bar{\pi}$ and is fully credible then we should observe $\beta=0$ in the UK data. That is, short term fluctuations should have no impact at all in the long run since in the long run it is believed that the Bank of England will always act to correct any deviation from target. But, as we shall see, if the target is not fully credible then the inflation pass through coefficient might not be zero. Indeed it might not even be a constant, but might vary with the level of inflation or its deviation from target. In this section, we will define $\beta_{h_{1}, h_{2}}$ to be the pass through of changes in inflation expectations at horizon $h_{1}$ to changes in inflation expectations at horizon $h_{2}$ (where $h_{1}$ and $h_{2}$ are chosen to be short-term and long-term, respectively). We are not necessarily assuming $\beta_{h_{1}, h_{2}}$ to be a constant parameter. Its magnitude could vary with expected inflation or other explanatory variables.

To define what we mean by anchored, contained and unmoored inflation, consider a standard decomposition of observed inflation $\left(\pi_{t}\right)$ into underlying inflation $\left(\pi_{t}^{*}\right)$ and a transitory component $\left(c_{t}\right)$ : 


$$
\pi_{t}=\pi_{t}^{*}+c_{t}
$$

where

$$
\begin{aligned}
E_{t}\left(\pi_{t+h}\right) & \rightarrow E_{t}\left(\pi_{t+h}^{*}\right) \\
E_{t}\left(c_{t+h}\right) & \rightarrow 0 \text { as } h \rightarrow \infty
\end{aligned}
$$

To illustrate the concept of anchored inflation expectations, consider Faust and Henderson (2004). This paper has a model of underlying inflation involving a target which is credible in the long run, $\bar{\pi}$ :

$$
\pi_{t}^{*}=\bar{\pi}(1-\theta)+\theta \pi_{t-1}^{*}+u_{t},
$$

where $u_{t}$ is a stationary residual and $|\theta|<1$. In this model, long run inflation expectations are $\bar{\pi}$ and, thus, inflation expectations are anchored about this target. Potter and Rosenberg (2007) show that inflation pass through takes the form:

$$
\beta_{h_{1}, h_{2}}=\theta^{h_{2}-h_{1}} .
$$

Thus, as $h_{2}$ gets larger, the inflation pass through coefficient goes to zero. This is the result described informally in the preceding paragraph: if the Bank of England's target is credible, then the inflation pass through coefficient should simply be a constant (and this constant goes to zero as $h_{2}$ increases).

An alternative to anchored inflation expectations are contained inflation expectations. In this case, the central bank's target is not fully credible, but the bank is believed to have a target interval outside which it is unlikely to let inflation go. In the US, the FOMC's combined mandate, involving inflation, output growth and interest rate concerns, preclude investors' belief in a precise inflation target, but it is possible that they still believe the FOMC will act if inflation gets either too high or too low. This suggests a target interval for inflation which would be reflected in investors' beliefs. In the UK, although there is no official target band in which inflation should lie, the Bank of England must write an open letter to the Chancellor of the Exchequer if inflation deviates by more than 1\% from target. This suggests that it is possible that investors believe that the Bank in practice has a target band inside which it strives to keep inflation. Potter (2007) develops a model 
where underlying inflation is restricted to lie in such a band. Formally, this paper has:

$$
\pi_{t}^{*}=\pi_{t-1}^{*}+u_{t}
$$

where

$$
u_{t} \sim T N\left(a-\pi_{t-1}^{*}, b-\pi_{t-1}^{*} ; 0, \sigma_{u}^{2}\right),
$$

where $T N\left(a-\pi_{t-1}^{*}, b-\pi_{t-1}^{*} ; 0, \sigma_{u}^{2}\right)$ is the truncated Normal distribution (i.e. the $N\left(0, \sigma_{u}^{2}\right)$ distribution truncated to the interval $\left.\left[a-\pi_{t-1}^{*}, b-\pi_{t-1}^{*}\right]\right)$. This model restricts underlying inflation to lie in the interval $[a, b]$, but within this interval underlying inflation follows a random walk (although it is simple to modify the model to allow for persistent but stationary behaviour). Potter and Rosenberg (2007) show how this model implies that the pass through coefficient depends on the current level of inflation. When these are near either $a$ or $b$, the central bank acts to return inflation towards the centre of the band and we have $\beta_{h_{1}, h_{2}}$ being small, implying fast mean reversion towards the middle of the interval. But, when inflation is well within the band, the central bank does not act and (unlike models of anchored expectations) $\beta_{h_{1}, h_{2}}$ equals one (or is large) indicating no (or very slow) reversion to the target. Thus, the empirical implications of contained inflation expectations are that the inflation pass through coefficient should not be a constant. Rather it will be high (possibly even near one) when inflation is roughly near the target, but will decrease (possibly even being near zero) as inflation deviates from target. ${ }^{2}$ In a study using US data (and a different modelling strategy than that used in this paper), Jochmann, Koop and Potter (2008) find evidence in favour of contained inflation expectations.

Finally, there are many papers (e.g. Stock and Watson (2007)), which have unmoored inflation expectations. These papers usually use US data and have an empirical motivation in that US inflation is often found to have a unit root. Thus, they use models for underlying inflation of the form:

$$
\pi_{t}^{*}=\pi_{t-1}^{*}+u_{t} .
$$

Potter and Rosenberg (2007) show that such models imply:

\footnotetext{
${ }^{2}$ Note that this model has the inflation pass through coefficient depending on the current level of inflation. In the absence of daily data on the CPI, short term inflation expectations are an effective proxy for actual inflation. This is what we use in our empirical work.
} 


$$
\beta_{h_{1}, h_{2}} \rightarrow 1 \text { as } h_{2} \rightarrow \infty \text { with } h_{1} \text { fixed. }
$$

For finite $h_{2}$ their formula for $\beta_{h_{1}, h_{2}}$ depends on the variances and persistences of the permanent $\left(\pi_{t}^{*}\right)$ and transitory $\left(c_{t}\right)$ components of inflation. However, if $h_{2}$ is set large enough for the transitory shock to dissipate, then $\beta_{h_{1}, h_{2}}=1$. Hence, the empirical implication of models of unmoored inflation expectations is that the pass through coefficients should be one (or close to one for finite $h_{2}$ ).

\section{The Data}

Both the US and the UK issue real (inflation adjusted) and nominal bonds and from these we can obtain daily data on inflation expectations. The US data runs from January 2, 2003 through June 9, 2008. The short term (2-5 year) and long term (9-10 year) inflation expectations variables were calculated from the US real and nominal Treasury security yields (from the TIPS market). The choices of starting date and 2-5 (9-10) as our definitions of short term (long term) are motivated by data availability and our desire to use data from highly liquid markets. In the UK, the Bank of England has extensive data on various yield curves. ${ }^{3}$ Most importantly for our purposes are data on the instantaneous implied inflation forward curve. ${ }^{4}$ Points on this curve can be used as measures of inflation expectations at different horizons. For the same considerations as for the US data, we use the four year implied inflation forward rate as our measure of short term inflation expectations and the ten year rate as our measure of long term inflation expectations. Details about the construction of the implied inflation forward curve are provided on the Bank of England website or Anderson and Sleath (2001). For our purposes, we note only that it is constructed using data on nominal and real forward interest rates. These are calculated using returns on nominal (conventional UK gilt-edged securities) and real (UK index-linked gilts) bonds of various maturities. The real bonds are adjusted using the RPI. Even though the Bank of England changed its official inflation target from 2.5\% (using the RPI) to $2.0 \%$ (using the CPI) in December, 2003, we informally refer to

\footnotetext{
${ }^{3}$ This data is available at http://www.bankofengland.co.uk/statistics/yieldcurve/archive.htm.

${ }^{4}$ This measure of implied inflation is also sometimes called inflation compensation or breakeven inflation.
} 
the inflation target as being 2.5\% throughout our sample. This is sensible since the RPI, in the UK, tends to yield inflation rates which are approximately $0.5 \%$ higher than CPI based inflation. The UK daily date runs from 4 January, 2000 to 2 June, 2008.

It is common practice to use the implied inflation forward curve to measure inflation expectations at different horizons, but the usual caveats apply. First, to interpret changes over time in the inflation forward curve as reflecting purely changes in inflation expectations, it must be the case that the inflation risk premium is roughly constant over time. Second, if the markets in the underlying bonds used to calculate the inflation forward curve are illiquid, then they may not provide a reliable underlying signal about inflation. Our choice of time span and horizons defining short- and long-term inflation expectations will minimize this latter problem.

\section{Econometric Models}

Our econometric modelling strategy is motivated by the theoretical considerations outlined previously. We want a model where an explanatory variable (i.e. short term inflation expectations, $\Delta x_{t}$ ) impacts on a dependent variable (i.e. the change in long term inflation expectations, $\Delta y_{t}$ ). This impact is measured by the inflation pass through coefficient. However, this coefficient may not be constant, but may vary depending on a range of possibilities (e.g. the level of inflation, the deviation of inflation from a target, etc.). We call these possibilities index variables, $z_{t}$. The trouble is that we do not know which of these index variables is relevant, nor do we know exactly how the inflation pass through coefficient will be related to the index variable. This suggests that standard linear regression methods are inappropriate and calls for some sort of flexible or semiparametric approach.

The smoothly mixing regression model of Geweke and Keane (2007) is an ideal framework for investigating these issues. This model given by:

$$
\Delta y_{t} \mid\left(v_{t}, s_{t}=j\right) \sim N\left(\alpha_{j}^{\prime} v_{t}, \sigma_{j}^{2}\right)
$$

for $j=1, . ., m$ and $t=1, \ldots, T$ where $\Delta y_{t}$ is the dependent variable and $v_{t}$ is a $p \times 1$ vector of observations on explanatory variables and $s_{t} \in\{1,2, . ., m\}$. In our case, $v_{t}$ contains an intercept and $\Delta x_{t}$. Equation (2) says that each observation is drawn from one of $m$ different Normal linear regression models (i.e. $\alpha_{j}$ and $\sigma_{j}^{2}$ can take on one of $m$ different values). This is an example of 
a Normal mixture model. The elements in the mixtures are denoted by the states, $s_{t} \in\{1,2, \ldots, m\}$.

The model is completed by specifying a form for $\operatorname{Pr}\left(s_{t}=j\right)$ for $j=$ $1, . ., m$. Geweke and Keane (2007) assume these state probabilities are modelled as depending on $z_{t}$ (which is a $q \times 1$ vector of observations on explanatory variables) using a simplified multinomial probit model. Using a standard random utility framework to we can define this model in terms of $w_{t}=\left(w_{t 1}, . ., w_{t m}\right)^{\prime}$ which is an $m \times 1$ vector of latent utilities. The model assumes

$$
w_{t}=\Gamma z_{t}+\zeta_{t}
$$

where $\zeta_{t}$ are independent $N\left(0, I_{m}\right)$ random vectors and

$$
s_{t}=j \text { if } w_{t j} \geq w_{t i} \text { for } i=1, . ., m .
$$

Bayesian inference in the smoothly mixing regressions model is described in Geweke and Keane (2007) who also provide an extensive discussion of the properties of this model. Briefly, mixtures of Normals are an extremely flexible way of modelling unknown distributions. Infinite mixture variants such as those involving Dirichlet processes are often referred to as "nonparametric" (e.g. Escobar and West, 1995). Geweke and Keane (2007) show how even mixing a small number of Normal distributions can result in a wide variety of shapes. It is worth noting that this model involves a scale mixture of Normals (i.e. $\sigma_{j}^{2}$ can vary across elements in the mixture). Such scale mixtures of Normals can allow for an error distribution which is very non-Normal (e.g. skewed and/or leptokurtic can easily be modelled) and can allow for very flexible patterns in the error variance (e.g. it can approximate stochastic volatility-type behaviour of many sorts).

However, in this paper, our interest lies not so much in the flexibility of the smoothly mixing regressions approach (useful though this is), but more in the fact that (3) ties the elements of the mixture to index variables. That is, the smoothly mixing regressions model could allow for a standard regression model with constant coefficient (if $m=1$ ). But, if the index variables, $z_{t}$, is short term inflation expectations, then it could allow for two different regression models to apply: one which holds when inflation expectations are high, the other when they are low. Or many other possibilities exist, depending on the definition of $z_{t}$. The key thing is that the smoothly mixing regressions 
model can uncover which (if any) index variable influences the pass through coefficient.

Motivated by the theoretical discussions of anchored, contained and unmoored inflation expectations, we consider the following index variables.

1. $t$ is natural time ordering

2. $x_{t}$

3. $\left|x_{t}-\bar{\pi}_{1}\right|$, where $\bar{\pi}_{1}$ is the Bank of England's official target $\left(\bar{\pi}_{1}=2.5 \%\right){ }^{5}$

4. $\left|x_{t}-\bar{\pi}_{2}\right|$, where $\bar{\pi}_{2}=\bar{x}$, the average level of short term inflation expectations $\left(\bar{\pi}_{2}=2.81\right.$ in the UK and 2.20 in the US).

5. $x_{t-1}$

6. $\left|x_{t-1}-\bar{\pi}_{1}\right|$

7. $\left|x_{t-1}-\bar{\pi}_{2}\right|$

8. $z_{t}$ contains all of the above explanatory variables.

We have now defined a class of very flexible models. Bayesian inference requires a prior and a method for posterior inference. In the appendices we describe the relatively noninformative prior we use in our empirical work and also provide evidence that our results are insensitive to prior by providing some results obtained using a training sample prior. Posterior inference is carried out using a Markov Chain Monte Carlo (MCMC) algorithm which is the same as that used in Geweke and Keane (2007). Hence, we do not present details, but refer the reader to the latter paper. Finally, we need a method for choosing between models. Following Geweke and Keane (2007), we do not use marginal likelihoods which can be sensitive to prior choice and unreliable when using noninformative priors. Instead we use cross-validation which does not suffer from these drawbacks. We use what Geweke and Keane (2007) call a modified cross-validated log scoring rule and provide details in the Technical Appendix.

\footnotetext{
${ }^{5}$ For the sake of completeness, we also include this index definition for the US even though the FOMC has not such explicit target.
} 


\section{$5 \quad$ Empirical Results}

We divide our empirical results into two sections. The first discusses which models are supported by the data, the second presents results on the inflation pass through coefficient and error variance.

\subsection{Model Comparison}

The modelling choices are the number of regimes (we considered $m=1,2,3$ and 4) and the choice between the seven index variable variables defined in Section 4 plus a model which includes all the Section 4 variables as index variables. Tables 1 and 2 present the modified cross-validated log scores (hereafter "log scores" for brevity) for the top ten models for the UK and the US, respectively.

Note first that, in both cases there is strong evidence of departures from the linear model given in (1) in the sense that the model with $m=1$ has vastly lower log scores and does not appear in our top ten lists. This statement holds true for both the UK and US data. However, other than this similarity, the UK and US log scores reveal different patterns. The UK data clearly prefers models where the index variable is associated with time. This can be seen in Table 1 where three of the top six models have time as the only index variable (and models lower than six in the top ten ranking have much lower log scores). Furthermore, the other models in the top six have all of the index variables included as explanatory variables. An examination of posterior means and standard deviations of the coefficients of $\Gamma$ (not reported here for the sake of brevity), indicate that the time index is always the most important explanatory variable in the multinomial probit model used to determine the state probabilities. For instance, for the model including all variables as index variables and $m=2$ we find the posterior mean of the coefficient on time to be almost three posterior standard deviations from zero. But, the coefficient on no other index is more than one standard deviation from zero.

In contrast to the UK results, the US results show more uncertainty over which model is supported. That is, the values of the log scores decrease quite slowly over the top ten models in Table 2 and two different choices of index variable both receive a fair bit of support. However, regardless of whether one looks at the top model (which includes all variables as index variables) or the other models which receive strong support, there is evidence that nonlinearities in the relationship between the changes in short-term and 
long-term inflation expectations is associated with the level of short term inflation expectation or perhaps its deviation from its mean.

We have now established that there are nonlinearities (of different sorts) in the UK and US data. But exactly what the implications of these nonlinearities are for the inflation pass through coefficient or different models of inflation expectations has not been established. It is to this issue we turn in the next section.

\begin{tabular}{|c|c|c|c|}
\hline \multicolumn{4}{|c|}{$\begin{array}{l}\text { Table 1: Modified Cross-Validated Log Score } \\
\text { for Top } 10 \text { Models (UK Data) }\end{array}$} \\
\hline No. & 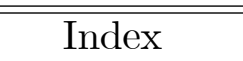 & $\bar{m}$ & $\begin{array}{l}\text { Log-score } \\
\end{array}$ \\
\hline 1 & $t$ & 2 & 1263.8428 \\
\hline 2 & all variables & 2 & 1249.1487 \\
\hline 3 & $t$ & 4 & 1245.1194 \\
\hline 4 & $t$ & 3 & 1243.1654 \\
\hline 5 & all variables & 4 & 1241.877 \\
\hline 6 & all variables & 3 & 1240.6137 \\
\hline 7 & $\left|x_{t-1}-\bar{\pi}_{2}\right|$ & 2 & 1206.112 \\
\hline 8 & $\left|x_{t}-\bar{\pi}_{2}\right|$ & 2 & 1205.0322 \\
\hline 9 & $\left|x_{t-1}-\bar{\pi}_{2}\right|$ & 3 & 1179.366 \\
\hline 10 & $\left|x_{t}-\bar{\pi}_{2}\right|$ & 3 & 1173.7165 \\
\hline \multicolumn{4}{|c|}{$\begin{array}{l}\text { Table 2: Modified Cross-Validated Log Scores } \\
\text { for Top } 10 \text { Models (US Data) }\end{array}$} \\
\hline No. & Index & $\mathrm{m}$ & Log-score \\
\hline 1 & All variables & 2 & 612.2447 \\
\hline 2 & $x_{t-1}$ & 3 & 607.2936 \\
\hline 3 & $x_{t}$ & 2 & 604.9173 \\
\hline 4 & $x_{t-1}$ & 2 & 604.4594 \\
\hline 5 & All variables & 4 & 604.4040 \\
\hline 6 & $\left|x_{t}-\bar{\pi}_{1}\right|$ & 2 & 602.1586 \\
\hline 7 & $\left|x_{t-1}-\bar{\pi}_{1}\right|$ & 2 & 598.6595 \\
\hline 8 & $\left|x_{t}-\bar{\pi}_{2}\right|$ & 4 & 597.9292 \\
\hline 9 & $t$ & 4 & 597.4763 \\
\hline 10 & $t$ & 3 & 596.2457 \\
\hline
\end{tabular}




\subsection{Inflation Pass Through and Other Features of In- terest}

Figures 1 through 3 plot the posterior mean and a measure of dispersion (the16th and 84th percentiles of the posterior) of the inflation pass through coefficient using the UK data in three different ways. All three figures use the best model (i.e. the one with the highest log score). For the UK this has $m=2$ and $z_{t}=t$. These three figures present the same information, but ordered in different ways (i.e. with different $\mathrm{X}$-axes). A first point to note is that all of these figures indicate that the pass through coefficient is neither near zero (as would be found if inflation expectations are firmly anchored) nor one (as would be found if inflation expectations were unmoored). Rather we are finding something in between. In our model, inflation pass through varies across observations, but we have strong posterior evidence that it is never less than 0.35 or above 0.70 in the UK.

Given the findings in Table 1, Figure 1 is the most revealing since it plots the inflation pass through coefficient over time. Here a substantial decrease in inflation pass through between mid 2002 and mid 2004 can be seen. All of the other models in our top 6 , which either use time as the index variable or all variables as indices yield this same pattern, but we do not provide figures for the sake of brevity. Figure 2 plots the inflation pass through coefficient against the level of short run inflation expectations (which can be interpreted as a proxy for the level of inflation). Unlike Figure 1, no patterns leap out in Figure 2. However, there is some indication that inflation pass through is lower when inflation is around $3 \%$ (slightly above average) or around $2 \%$ (very low). The latter of these findings would be consistent with Potter's (2007) model of contained inflation expectations, but the former is not. Figure 3 plots the inflation pass through coefficient against $\left|x_{t}-\bar{\pi}_{2}\right|$. The picture found here is not consistent with the specific theory of contained inflation expectations outlined previously (as this would imply the pass through coefficient should decline with $\left.\left|x_{t}-\bar{\pi}_{2}\right|\right)$.

In summary, with the UK data there is strong evidence that the inflation pass through changes over time and general evidence in favour of inflation expectations being contained in some manner. However, the evidence is not totally consistent with the simple version of the contained inflation expectations hypothesis outlined in Section 2. Anchored or unmoored inflation expectations receive no support in the UK. 


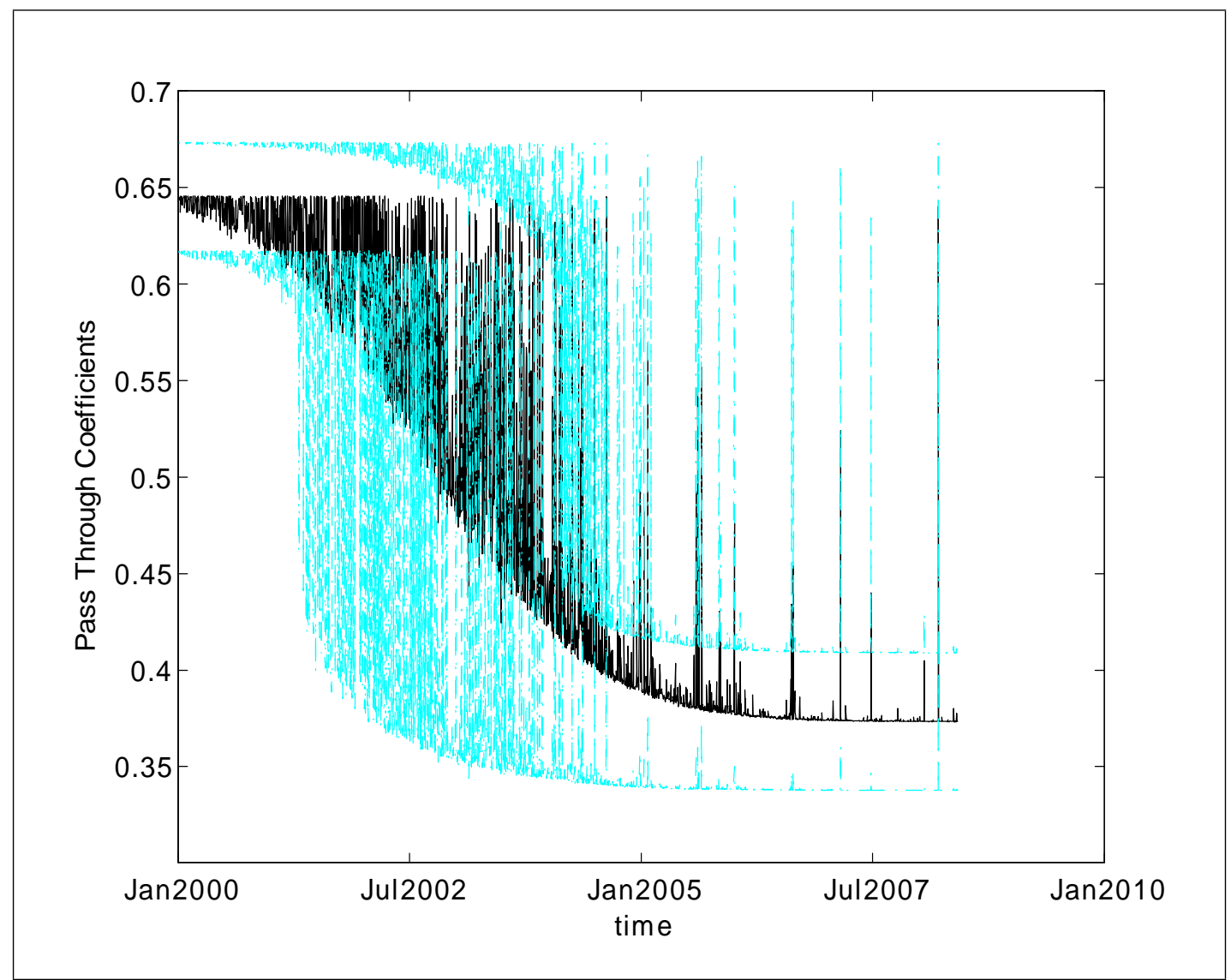

Figure 1: UK Pass Through Coefficient. Posterior mean (black line) and 16th-84th percentiles (blue lines) 


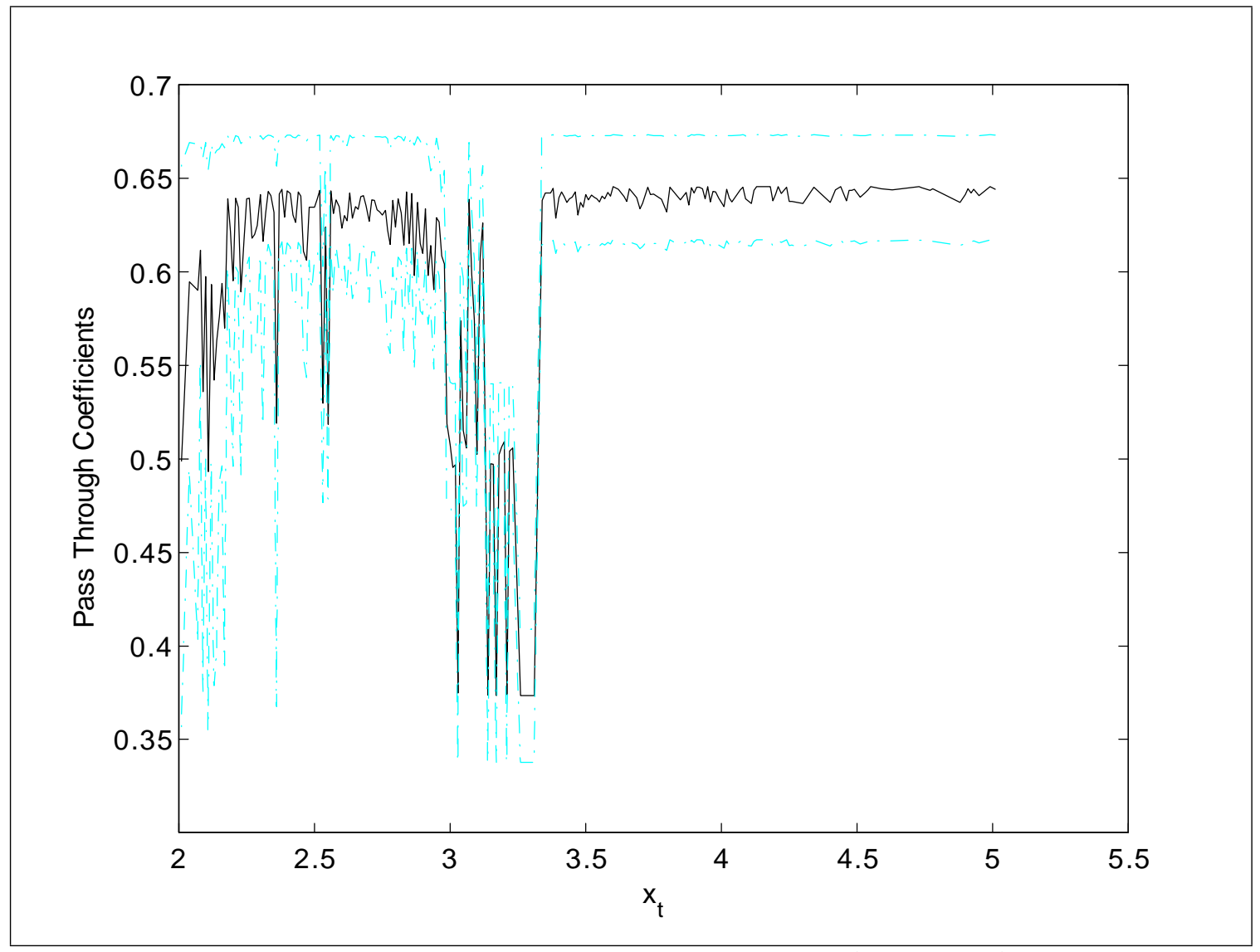

Figure 2: UK Pass Through Coefficient. Posterior mean (black line) and 16th-84th percentiles (blue lines) 


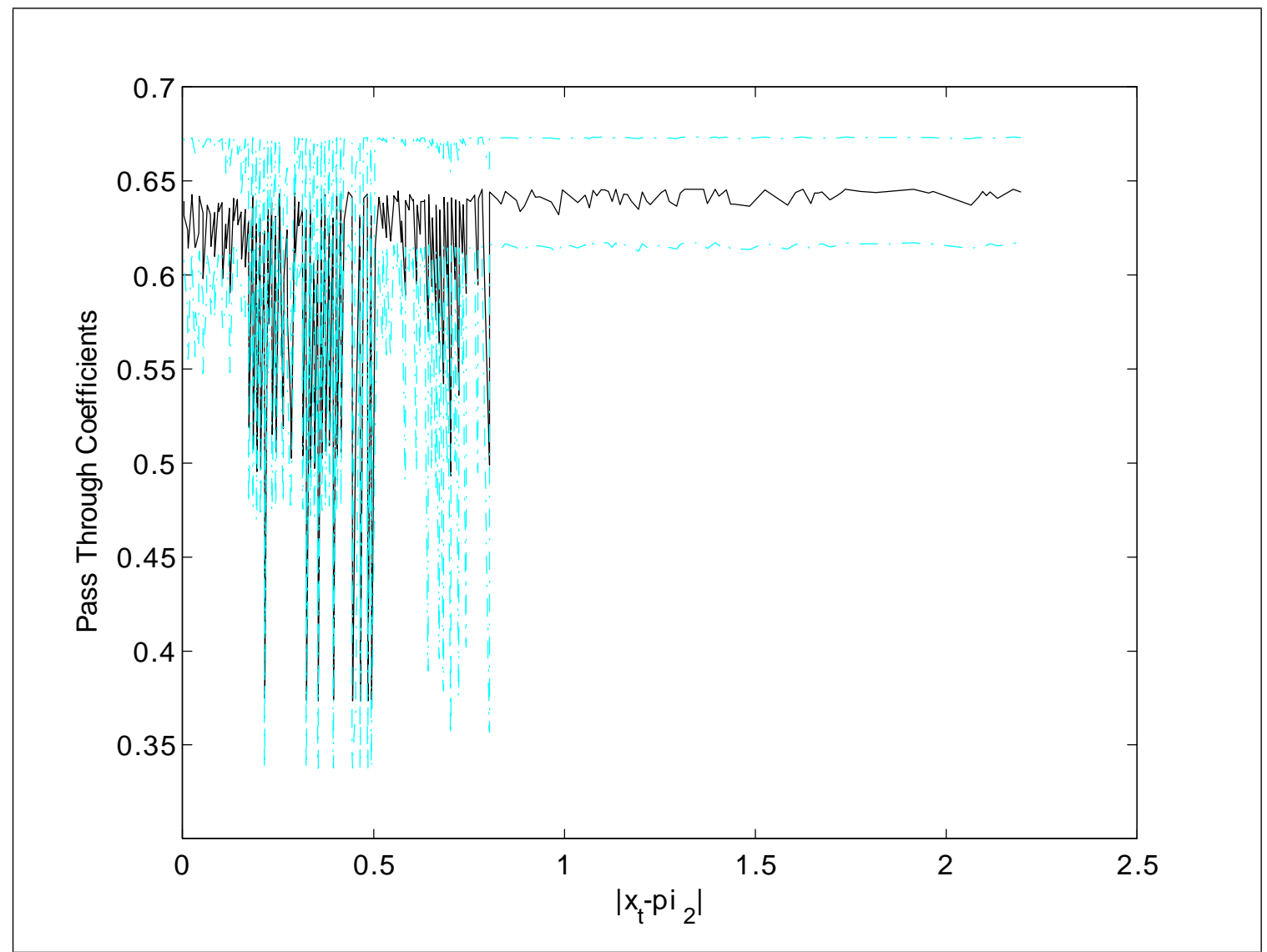

Figure 3: UK Pass Through Coefficient. Posterior mean (black line) and 16th-84th percentiles (blue lines)

Figures 4 through 6 summarize our US findings. They are in the same format as Figures 1 through 3 in that they choose the best model and plot the inflation pass through coefficient against three different $\mathrm{X}$-axes. In the US case, the best model has $z_{t}$ containing all the Section 4 variables and $m=2$. These figures do suggest some interesting patterns. Jochmann, Koop and Potter (2008), using a different econometric methodology, present evidence in favour of the contained inflation expectations hypothesis. And, insofar as Figures 4 through 6 show that the pass through coefficient is almost everywhere small (often near zero and very rarely above 0.4 ), our smoothly mixing regressions model is also finding evidence of contained expectations. Figure 4 provides some evidence that the pass through coefficient was lower at the 
beginning of our sample than at the end (an opposite finding from the UK). But the strongest evidence is for a pass through coefficient which varies with short term inflation expectations in some way. Overall, we are finding some evidence in favour of the simple version of the contained inflation expectations hypothesis described in Section 2. Remember that this said that the pass through coefficient should go become smaller as departures of inflation from its mean grew large in either the positive or negative direction. Figure 6 , which plots pass through against $\left|x_{t}-\bar{\pi}_{2}\right|$, exhibits a pattern consistent with this. Although the posterior mean is somewhat erratic (and point-wise credible intervals are sometimes wide) at low values of $\left|x_{t}-\bar{\pi}_{2}\right|$, the overall picture that comes out is one that is consistent with the model of contained inflation expectations outlined in Section 2. However, models using $x_{t}$ or $x_{t-1}$ as indices yield higher log scores than those using $\left|x_{t}-\bar{\pi}_{1}\right|$ or $\left|x_{t}-\bar{\pi}_{2}\right|$ or their lags. If we look at Figure 5, which plots the pass through coefficient against $x_{t}$, we can see why this is. Very low values of short term inflation expectations (which imply large negative deviations from $\bar{\pi}_{2}$ ) lead to pass through coefficients which are indeed near zero, while pass through coefficients are at their maximum near $\bar{\pi}_{2}$. These findings are consistent with our model of contained inflation expectations. However, pass through coefficients corresponding to large positive deviations of inflation from $\bar{\pi}_{2}$, are only slightly below their maximum values. This indicates an asymmetry which is not perfectly consistent with using $\left|x_{t}-\bar{\pi}_{1}\right|$ or $\left|x_{t}-\bar{\pi}_{2}\right|$ or their lags as indices. Nevertheless, Figures 5 and 6 indicate moderately strong support for the contained inflation expectations hypothesis. There is no evidence in favour either of unmoored or firmly anchored inflation expectations. 


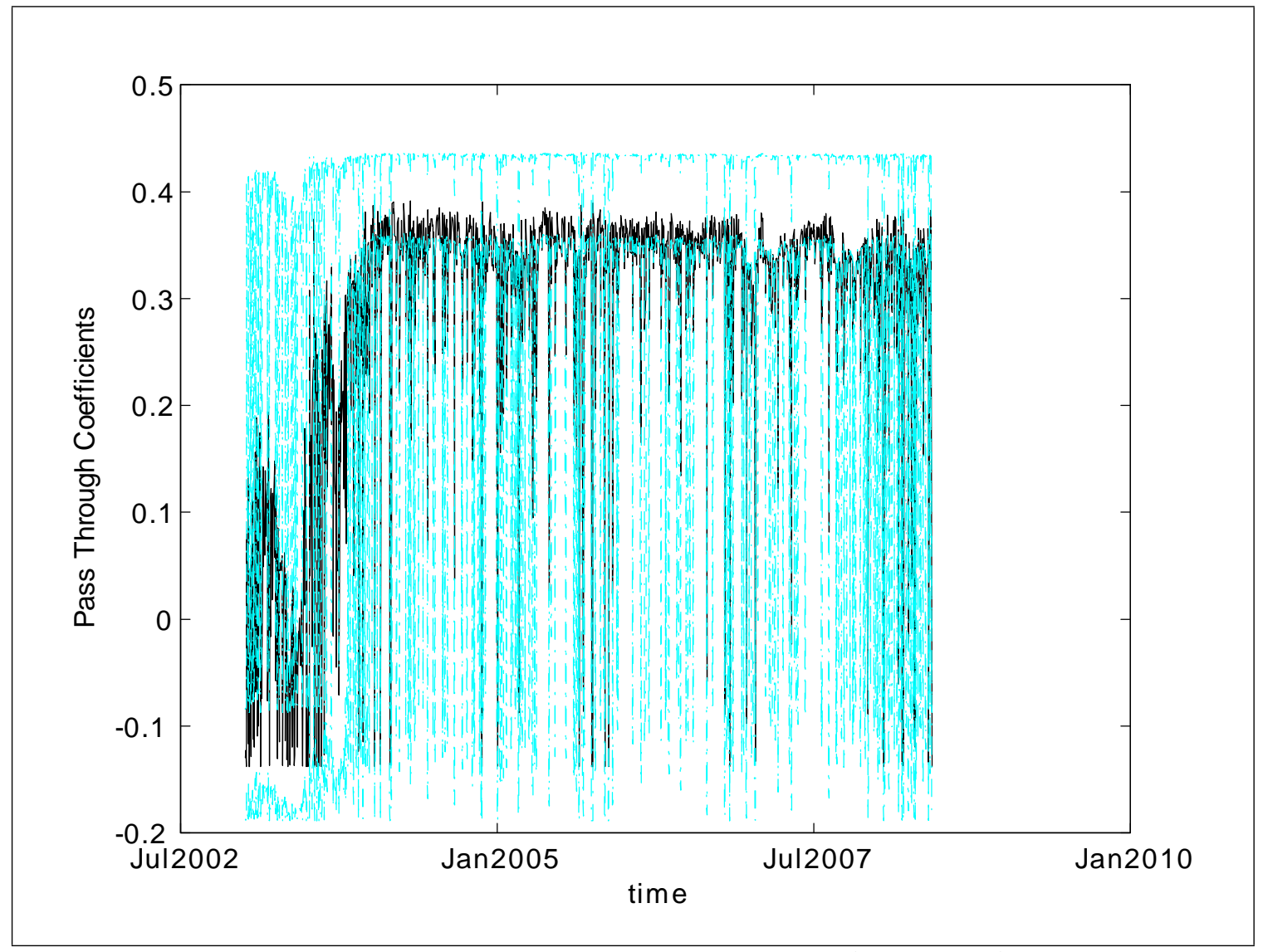

Figure 4: US Pass Through Coefficient. Posterior mean (black line) and 16th-84th percentiles (blue lines) 


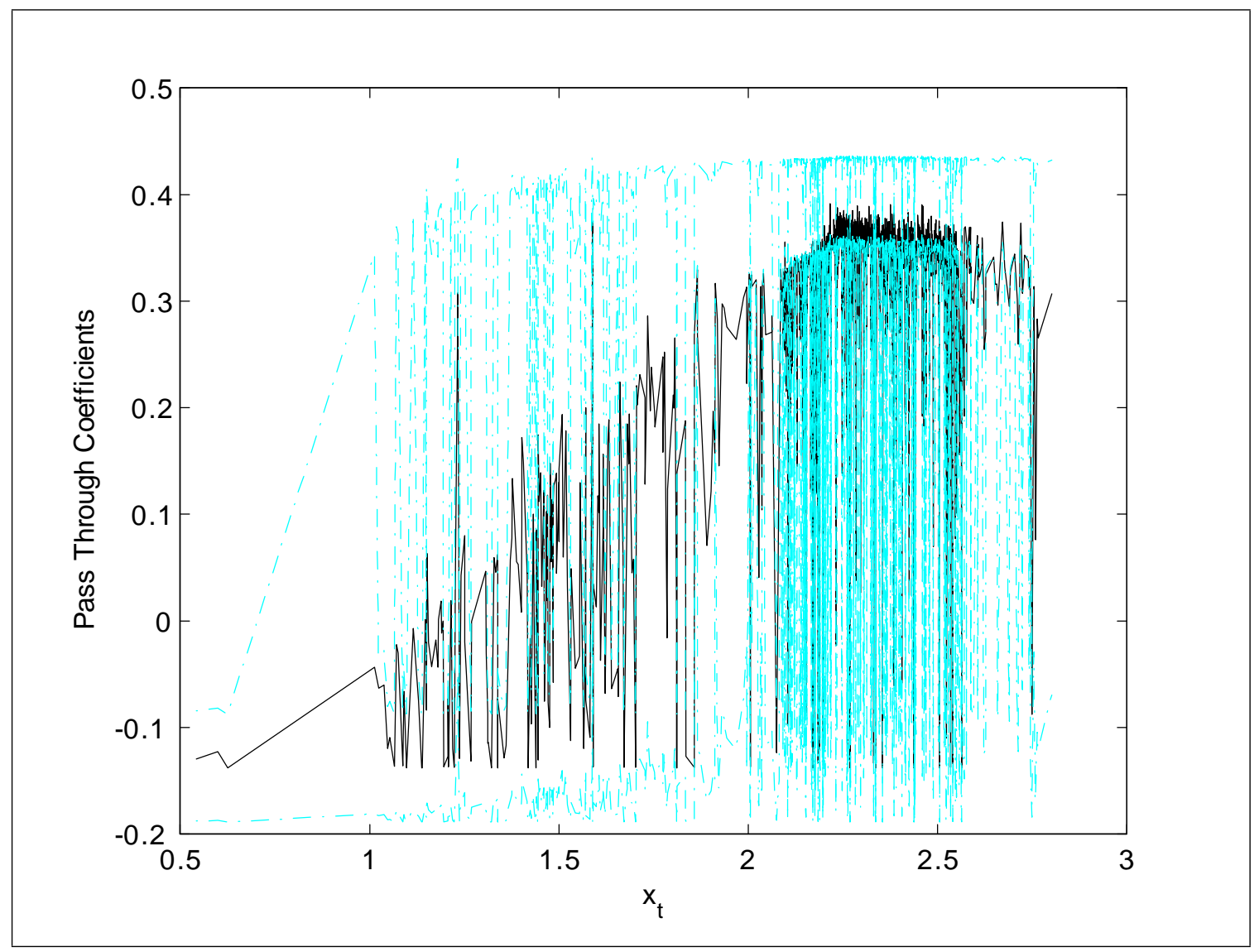

Figure 5: US Pass Through Coefficient. Posterior mean (black line) and 16th-84th percentiles (blue lines) 


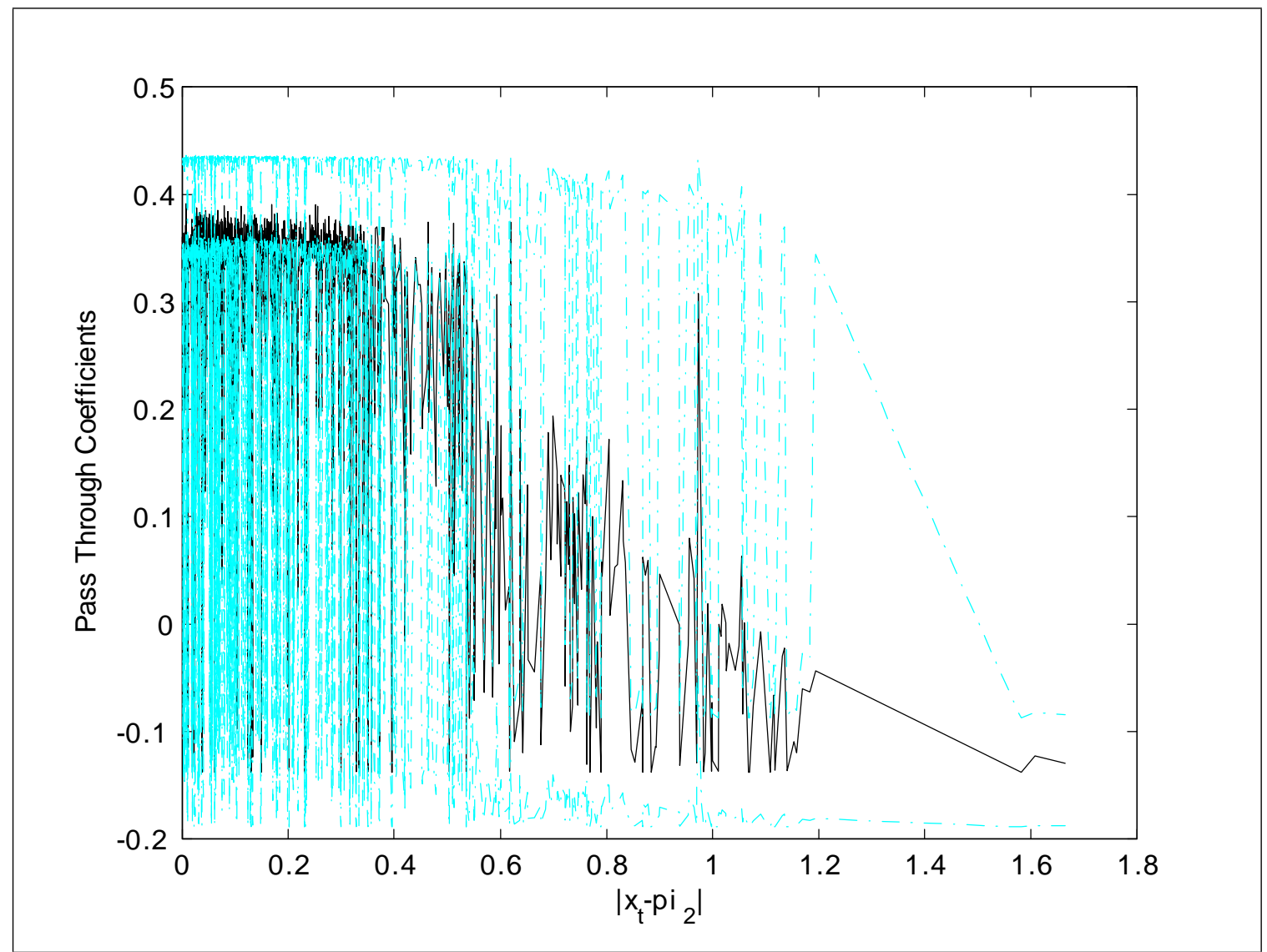

Figure 6: US Pass Through Coefficient. Posterior mean (black line) and 16th-84th percentiles (blue lines)

Figures 7 through 12 present plots of the error variance in the same format as Figures 1 through 6 . That is, they all use results for the best model, the first three graphs are for the UK and the last three the US and they have different X-axes. For the UK, the patterns in the error variance are very similar as for the pass through coefficient itself. That is, Figure 7 shows a big drop in the error variance at roughly the same time as the big drop as the inflation pass through coefficient. We stress that this is not an artifact of our econometric model. Our model would easily be capable of picking up breaks in the pass through coefficient and error variance at different points in time. There is also some (much weaker) evidence in favour of volatility being related to the level of inflation and its deviation from target. 


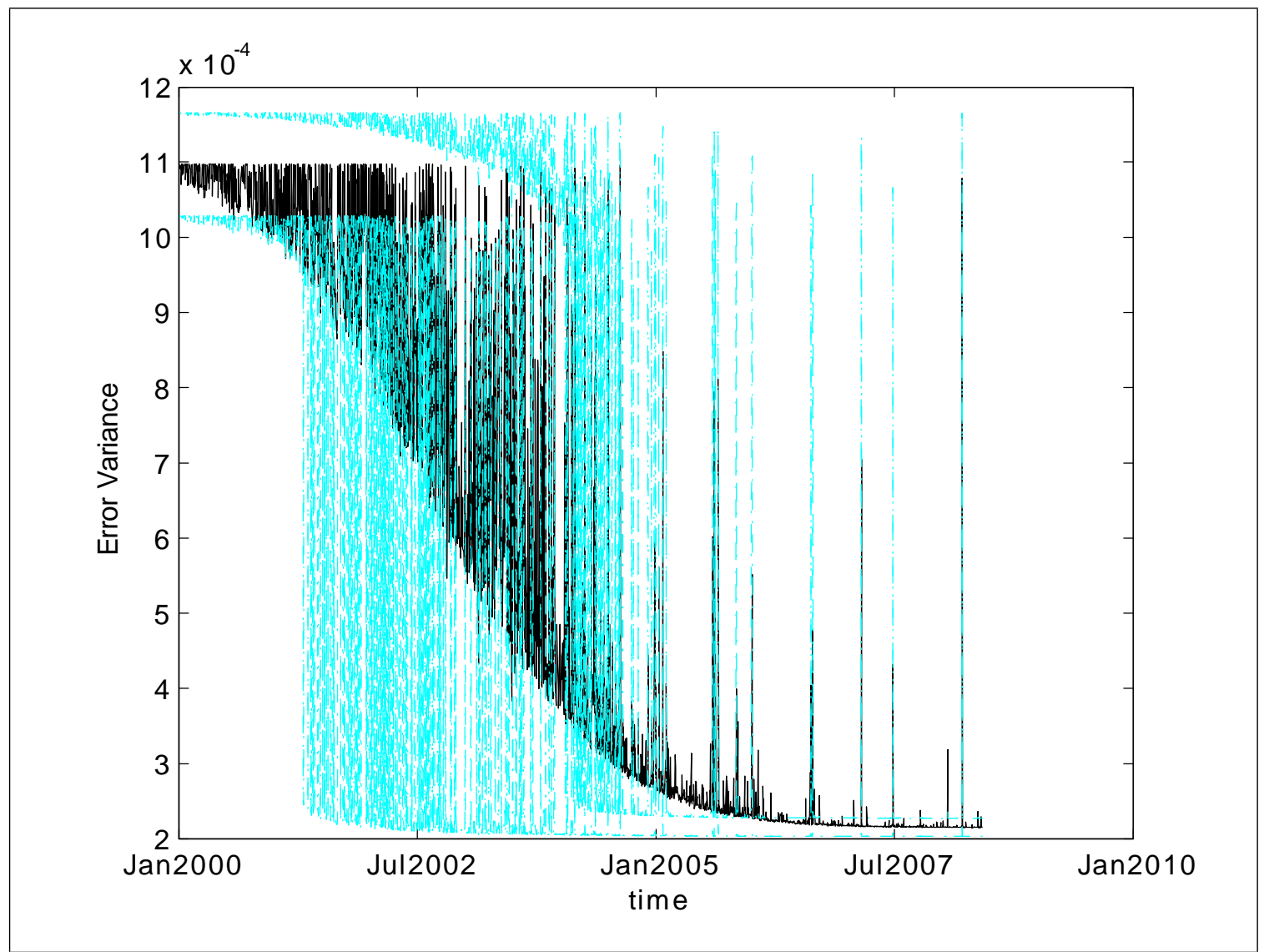

Figure 7: UK Error Variance. Posterior mean (black line) and 16th-84th percentiles (blue lines) 


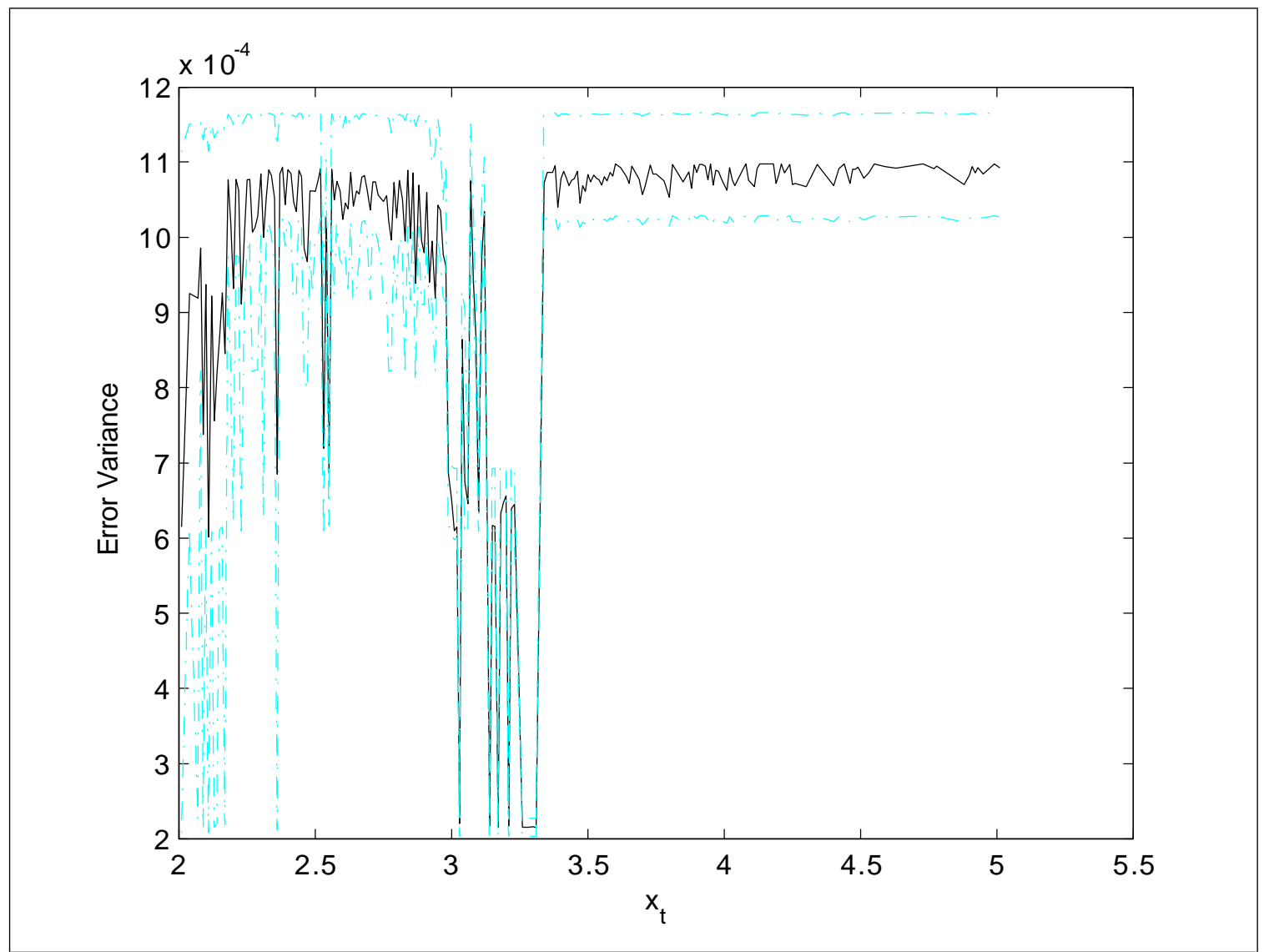

Figure 8: UK Error Variance. Posterior mean (black line) and 16th-84th percentiles (blue lines) 


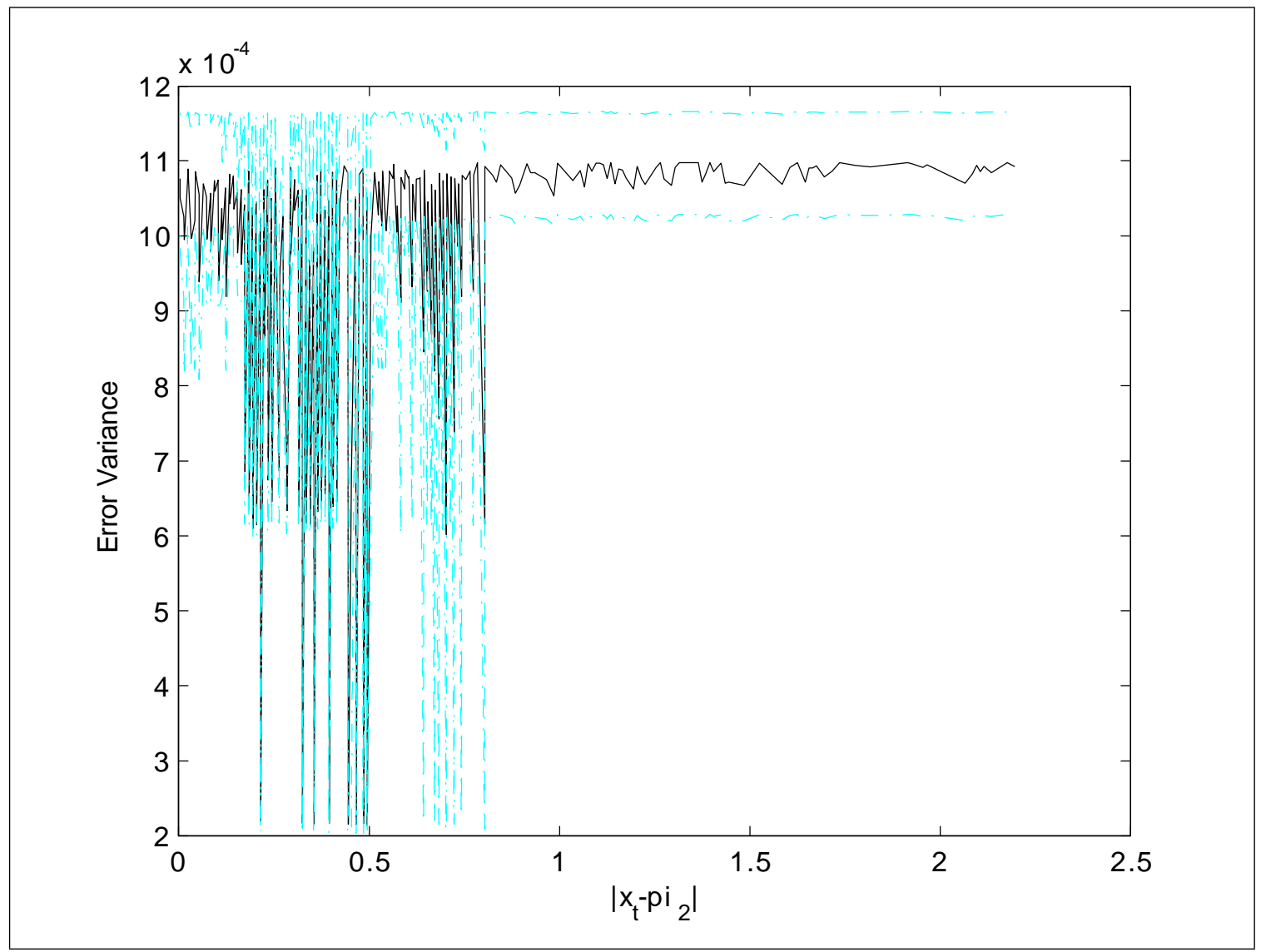

Figure 9: UK Error Variance. Posterior mean (black line) and 16th-84th percentiles (blue lines) 


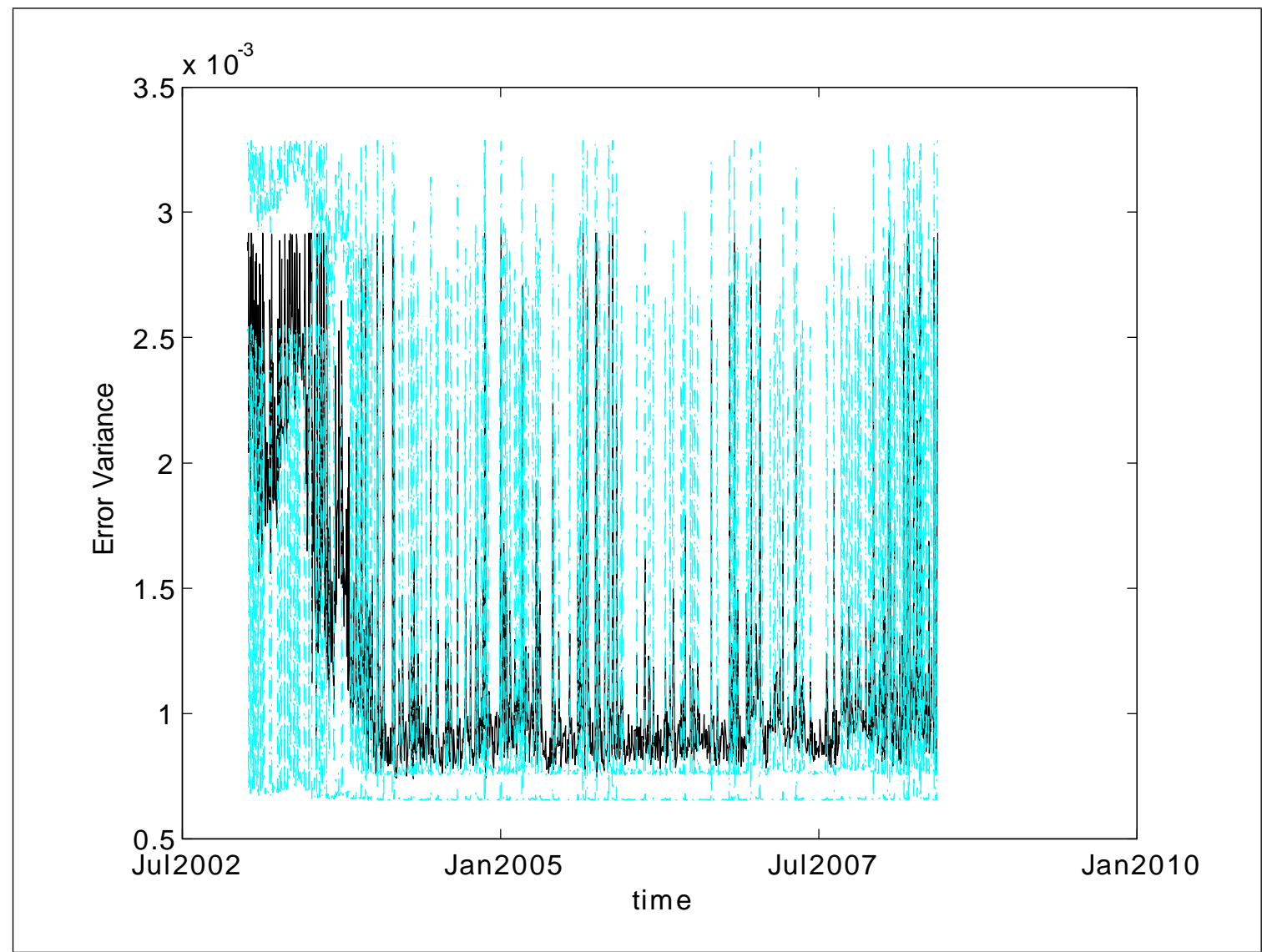

Figure 10: US Error Variance. Posterior mean (black line) and 16th-84th percentiles (blue lines) 


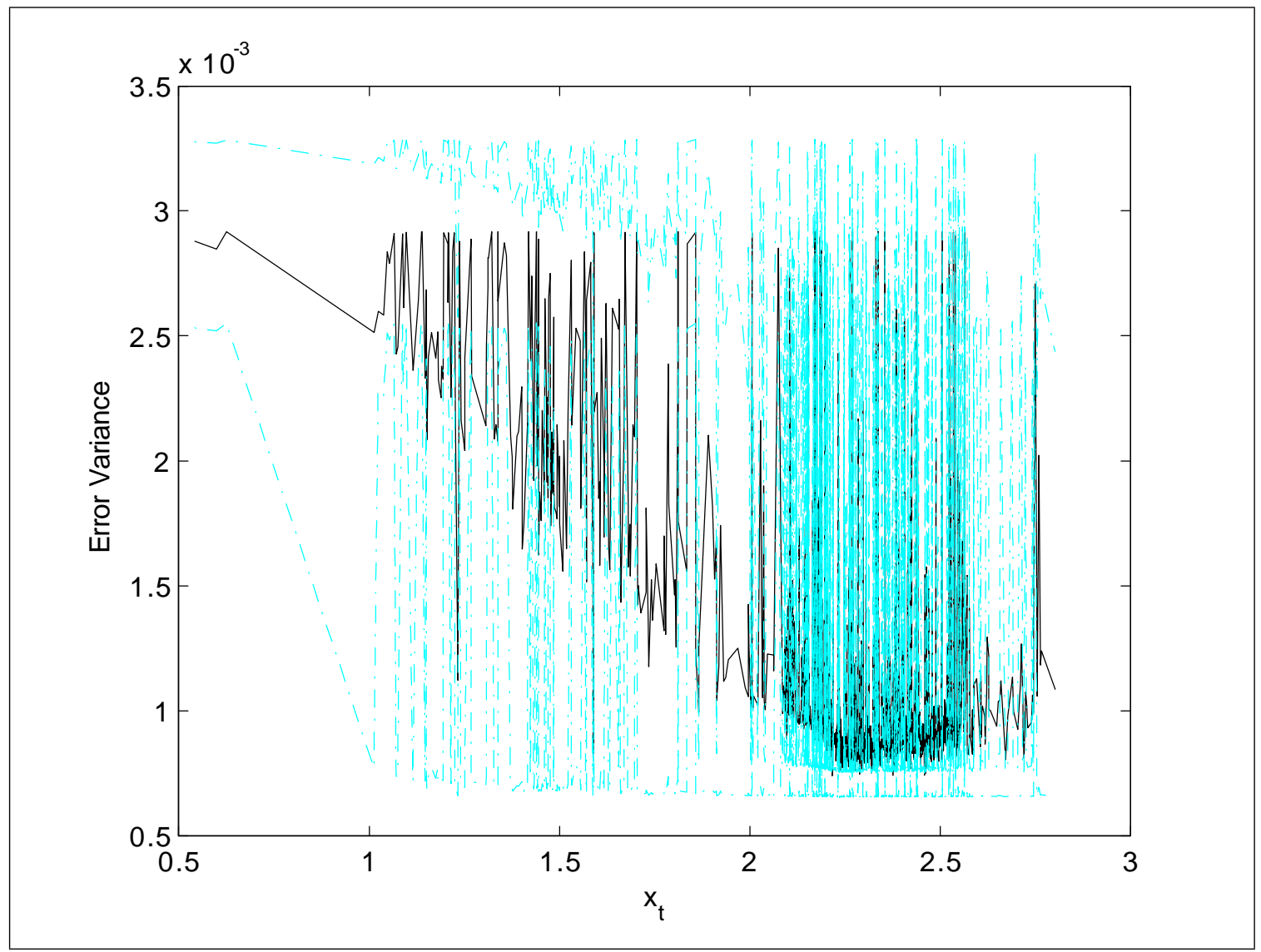

Figure 11: US Error Variance. Posterior mean (black line) and 16th-84th percentiles (blue lines) 


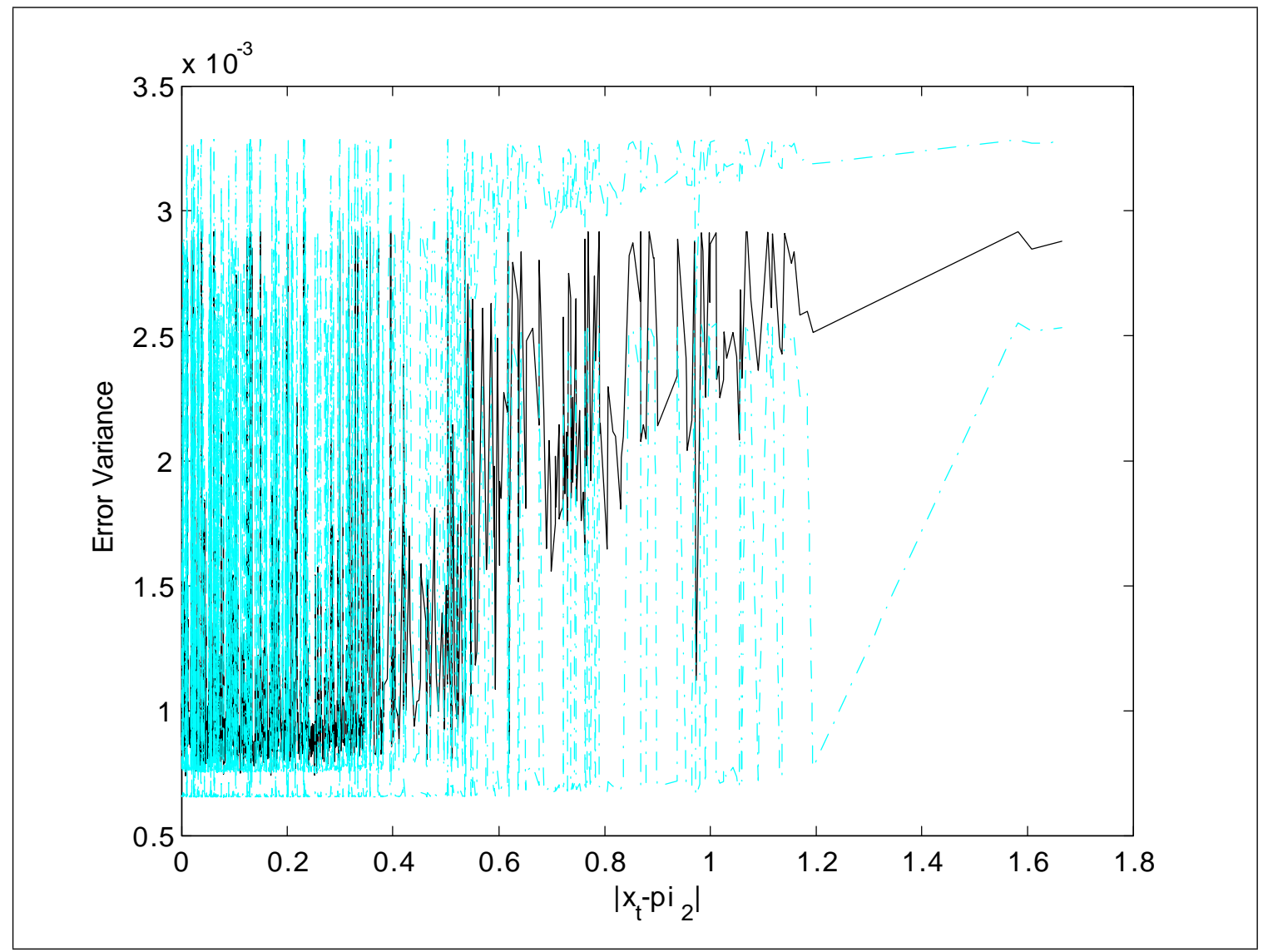

Figure 12: US Error Variance. Posterior mean (black line) and 16th-84th percentiles (blue lines)

For the US there is less evidence of heteroskedasticity. Figure 10 indicates that the error variance was bigger near the start of the sample than at the end, whereas Figures 11 indicates that the error variance becomes high when short term inflation expectations are low. Figure 12, which plots pass through against the absolute deviation of short term inflation expectations from the mean, indicates a slight tendency for the error variance to rise as this increases.

The figures above always present results for the best model. For the sake of brevity, we do not present results for other models with high log scores, nor do we present results which average across models. However, the patterns described above hold in all such cases. Furthermore, although the results 
above are found using one (relatively noninformative) prior, the Empirical Appendix shows that results are robust to prior choice.

\section{Discussion and Conclusion}

What should we conclude from the empirical results presented in the previous section? From an econometric point of view, our results show the benefits of the smoothly mixing regressions framework. Clearly, there are nonlinearities in these data sets, so working with linear regression models is potentially misleading. Furthermore, a priori, it is unclear what form the nonlinearity would take. An advantage of our smoothly mixing regressions model was that it allowed us to discover what form the nonlinearity took. In the UK, the most important variation in the pass through coefficient is over time, in the US it is over the absolute deviation of inflation from its mean.

From an economic point of view, our findings can be summarized as follows. We can definitely say that for neither the US nor the UK is the inflation pass through coefficient ever near one, as would be implied by unmoored inflation expectations. Nor is it consistently near zero as implied by anchored inflation expectations. Instead inflation expectations seem to be contained, but in different ways, in the two countries. The simple model of contained inflation expectations presented in Section 2 does receive support in the US data, but not in the UK. In the UK, our predominant finding is that both the inflation pass through coefficient and the error variance is decreasing over time. This is consistent with a story where investors become more and more confident that the Bank of England will act to correct any deviations of inflation from target as time goes by. 


\section{References}

Anderson, N. and Sleath, J. (2001). "New estimates of the UK real and nominal yield curves," Bank of England Working Paper 126.

Escobar, M. and West, M. (1995). "Bayesian density estimation using mixtures," Journal of the American Statistical Association, 90, 577-588.

Faust, J. and Henderson, D. (2004). "Is inflation targeting best-practice monetary policy?" Federal Reserve Bank of St. Louis Review, 86, 117.

Geweke, J. and Keane, M. (2007). "Smoothly mixing regressions," Journal of Econometrics, 138, 252-291.

Gurkaynak, R., Levin, A. and Swanson, E. (2006). "Does inflation targeting anchor long-run inflation expectations?" Federal Reserve Bank of San Francisco, working paper 2006-09.

Jochmann, M., Koop, G. and Potter, S. (2008). "Modeling the dynamics of implied inflation compensation"

Potter, S. (2007). "A bounded model of inflation," Federal Reserve Bank of New York, Staff Reports.

Potter, S. and Rosenberg, J. (2007). "Are U.S. inflation expectations anchored, contained or unmoored?" manuscript.

Stock, J. and Watson, M. (2007). "Why has U.S. inflation become harder to forecast?" Journal of Money, Credit and Banking, 39, 3-33. 


\section{Technical Appendix}

Our econometric methods follow Geweke and Keane (2007) and complete details are given there. Here we describe our prior hyperparameter choices along with our method of choosing models. We refer the reader to Geweke and Keane (2007) for a description of the MCMC algorithm used to carry out Bayesian inference in the smoothly mixing regressions model.

Our modelling framework is given in (2) and (3) and the eight choices for index variables given in Section 4 . The parameters are the error variance $\left(\sigma_{j}^{2}\right)$ and the coefficients $\left(\alpha_{j}\right)$ in state $j$ for $j=1, \ldots, m$ and the coefficients $(\Gamma)$ of the restricted multinomial probit specification used to model the state probabilities.

We use the following priors:

$$
\alpha_{j} \sim N\left(\underline{\alpha}, \underline{H}_{\alpha}^{-1}\right)
$$

and

$$
\underline{s}^{2} \sigma_{j}^{-2} \mid\left(\underline{s}^{2}, \underline{\nu}\right) \sim \chi^{2}(\underline{\nu}) .
$$

As in Geweke and Keane (2007), $\Gamma$ in the latent multinomial probit model is identified by restricting $\iota_{m}^{\prime} \Gamma=0^{\prime}$. Specifically, define an $m \times m$ orthonormal matrix $P=\left[\begin{array}{ll}p_{1} & P_{2}\end{array}\right]$ in which $p_{1}=\iota_{m} m^{-\frac{1}{2}}$. Then define $\Gamma^{*}=P_{2}^{\prime} \Gamma$. Letting $\gamma_{j}^{*}$ be the $j^{\text {th }}$ column of the matrix $\Gamma^{*}$, we have a prior:

$$
\gamma_{j}^{*} \sim N\left(0, \underline{H}_{\gamma^{*}}^{-1}\right)
$$

We have experimented with different choices for the prior hyperparameters $\underline{\alpha}, \underline{H}_{\alpha}, \underline{s}^{2}, \underline{\nu}$ and $\underline{H}_{\gamma^{*}}$, including training sample priors. The results presented in the body of the paper involve the relatively noninformative choices of $\underline{\alpha}=\left[\operatorname{mean}\left(\Delta y_{t}\right) \quad 0\right], \underline{H}_{\alpha}=\left[\begin{array}{cc}0.01 & 0 \\ 0 & 0.01\end{array}\right], \underline{s}^{2}=0.01, \underline{\nu}=2$ and $\underline{H}_{\gamma^{*}}=0.01 I$. We find that the posterior results of the pass through coefficients are robust to prior choice. The following empirical appendix presents some evidence to support this claim.

We use the modified cross-validated log scoring rule of Geweke and Keane (2007) to select $m$ and the index variable. This involve randomly selecting a sample of size $T_{1}$ to be used for estimation, leaving a remaining $T-T_{1}$ for cross-validation. The metric for comparing models then is:

$$
\sum_{t=T_{1}+1}^{T} \log \left[p\left(\Delta y_{t} \mid Y_{T_{1}}, v_{t}, z_{t}\right)\right]
$$


where $Y_{T_{1}}$ denotes the $T_{1}$ observations on the dependent variable used for estimation. The notation in the previous equation denotes the predictive density evaluated at the actual realization $\Delta y$. This metric can be estimated in our MCMC algorithm since, if we denote all model parameters by $\lambda$, we have $p\left(\Delta y_{t} \mid Y_{T_{1}}, v_{t}, z_{t}, \lambda\right)$ being Normal and we can simply average these Normal densities over our MCMC draws of $\lambda$.

The empirical results in the paper choose $T_{1}$ such that $75 \%$ of the observations are used for estimation and $25 \%$ for cross-validation. This $25 \%$ of the observations is randomly chosen one time and the same set of observations is withheld for every model. Results withholding $50 \%$ of the observations for cross-validation are very similar. The final empirical results for each model (such as those presented in Figures 1 through 12) are based on the full sample. 


\section{Empirical Appendix}

In order to convince our reader that our results are robust to prior choice, we present results using a training sample prior. This prior uses the first 200 observations to produce OLS quantities, $\widehat{\alpha}, \widehat{V}_{\alpha}$ and $s^{2}$. It sets $\underline{\alpha}=\widehat{\alpha}, \underline{H}_{\alpha}^{-1}=$

$10 \widehat{V}_{\alpha}, \underline{s}^{2}=2 s^{2}, \underline{\nu}=2$ and $\underline{H}_{\gamma^{*}}=0.01 I_{q}$. A training sample prior of identical form, but using the last 200 observations yields very similar results (not presented here).

For the sake of brevity, we do not present modified cross-validated log scores in tables analogous to Tables 1 and 2. For the UK data, the list of top 10 models using the training sample prior is identical to Table 1. For the US, it is quite similar except that models with index variable $\left|x_{t}-\bar{\pi}_{1}\right|$ and its lag do better, when compared to models with $x_{t}$ and its lag, than in Table 2. This slightly strengthens support for the view that the US data supports the contained inflation expectations hypothesis. However, a model with all variables included in $z_{t}$ remains the top model.

For the UK data, Figures A1 and A2 present the inflation pass through coefficient and error variance for the best model in the same format as Figures 1 and 7, respectively. Similarly, for the US data, Figures A3 and A4 should be compared with Figures 6 and 12, respectively. Comparing the figures in the text with those in this appendix, one can see that they are very similar. 


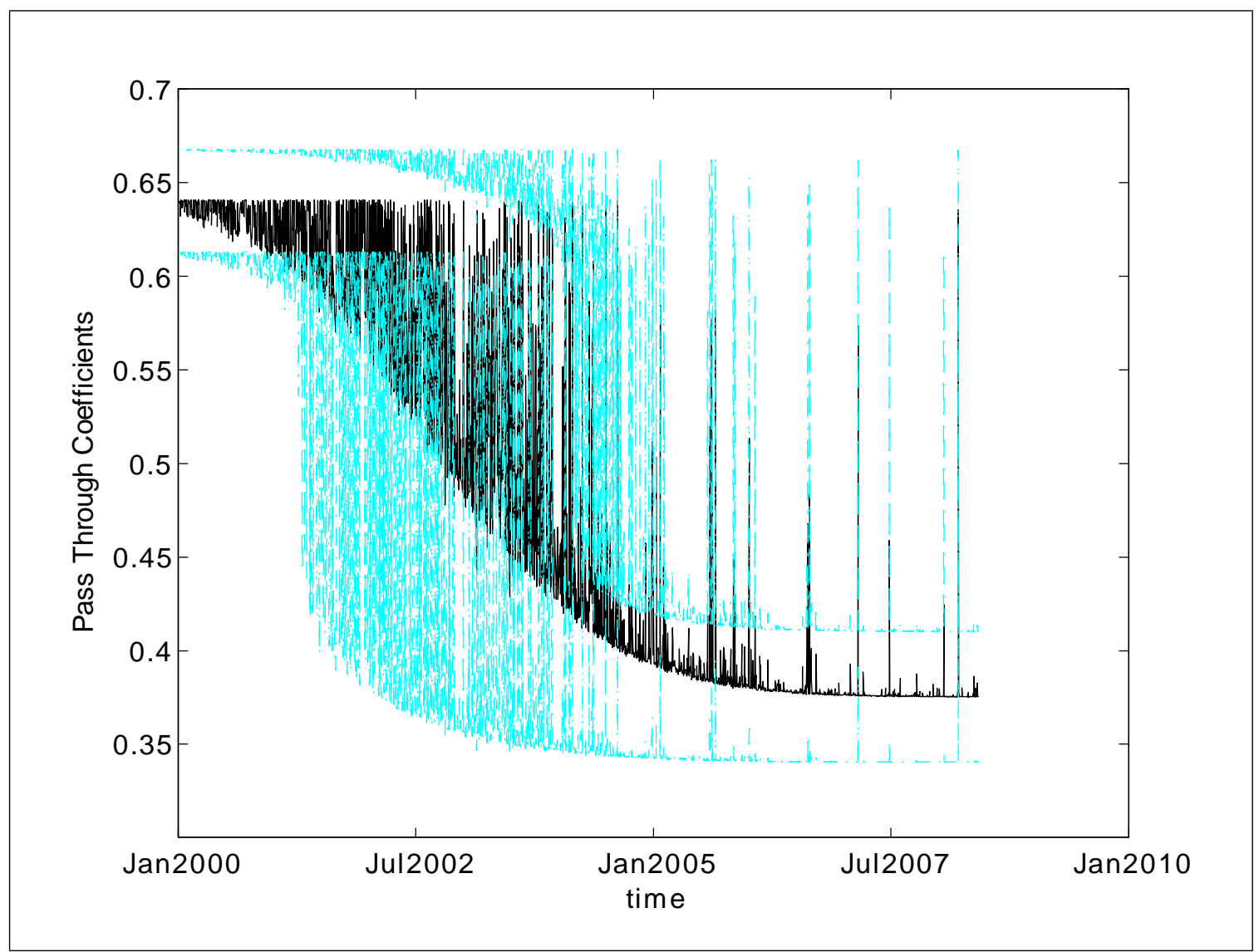

Figure A1: UK Pass Through Coefficient. Posterior mean (black line) and 16th-84th percentiles (blue lines) 


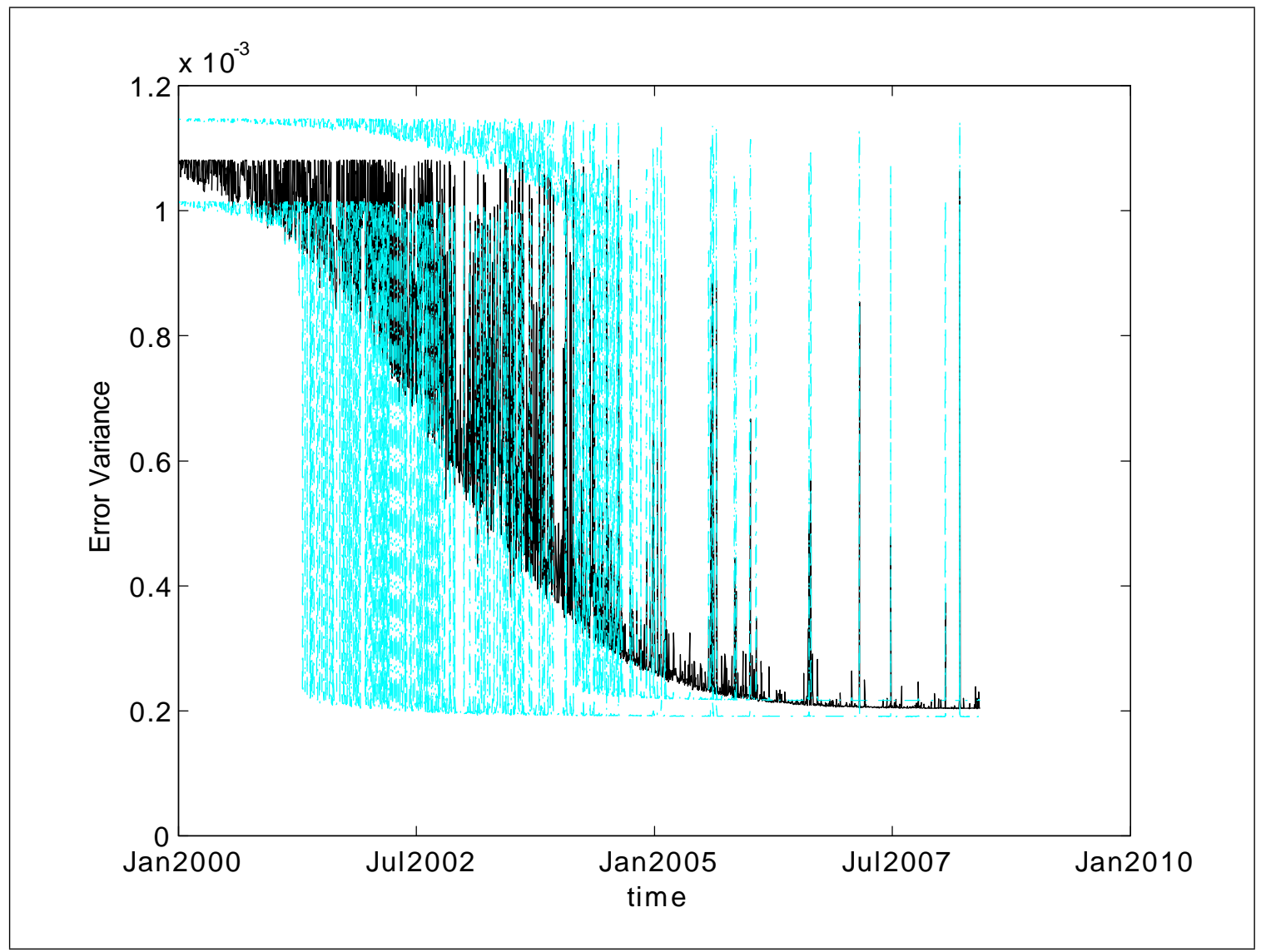

Figure A2: UK Error Variance. Posterior mean (black line) and 16th-84th percentiles (blue lines) 


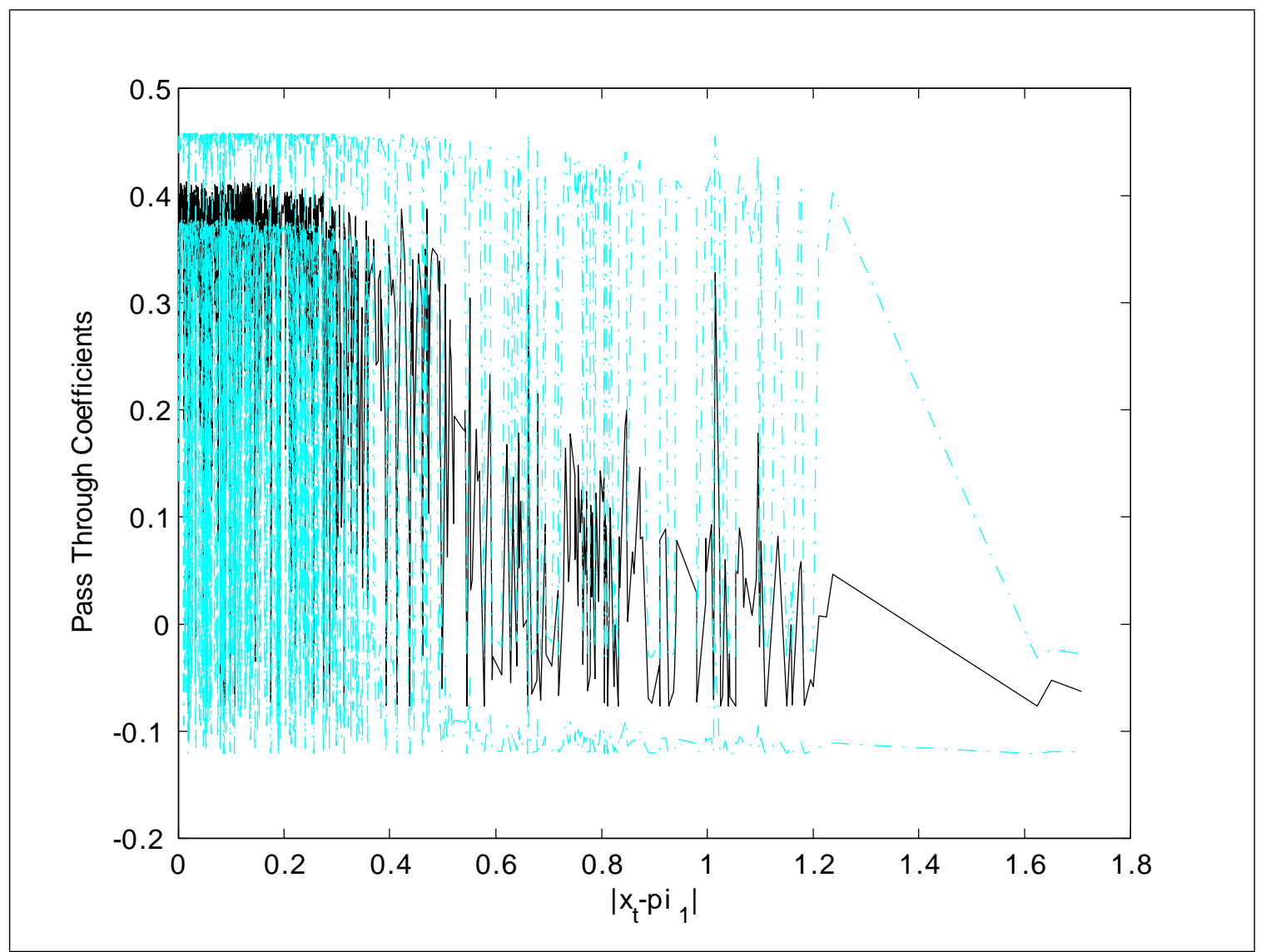

Figure A3: US Pass Through Coefficient. Posterior mean (black line) and 16th-84th percentiles (blue lines) 


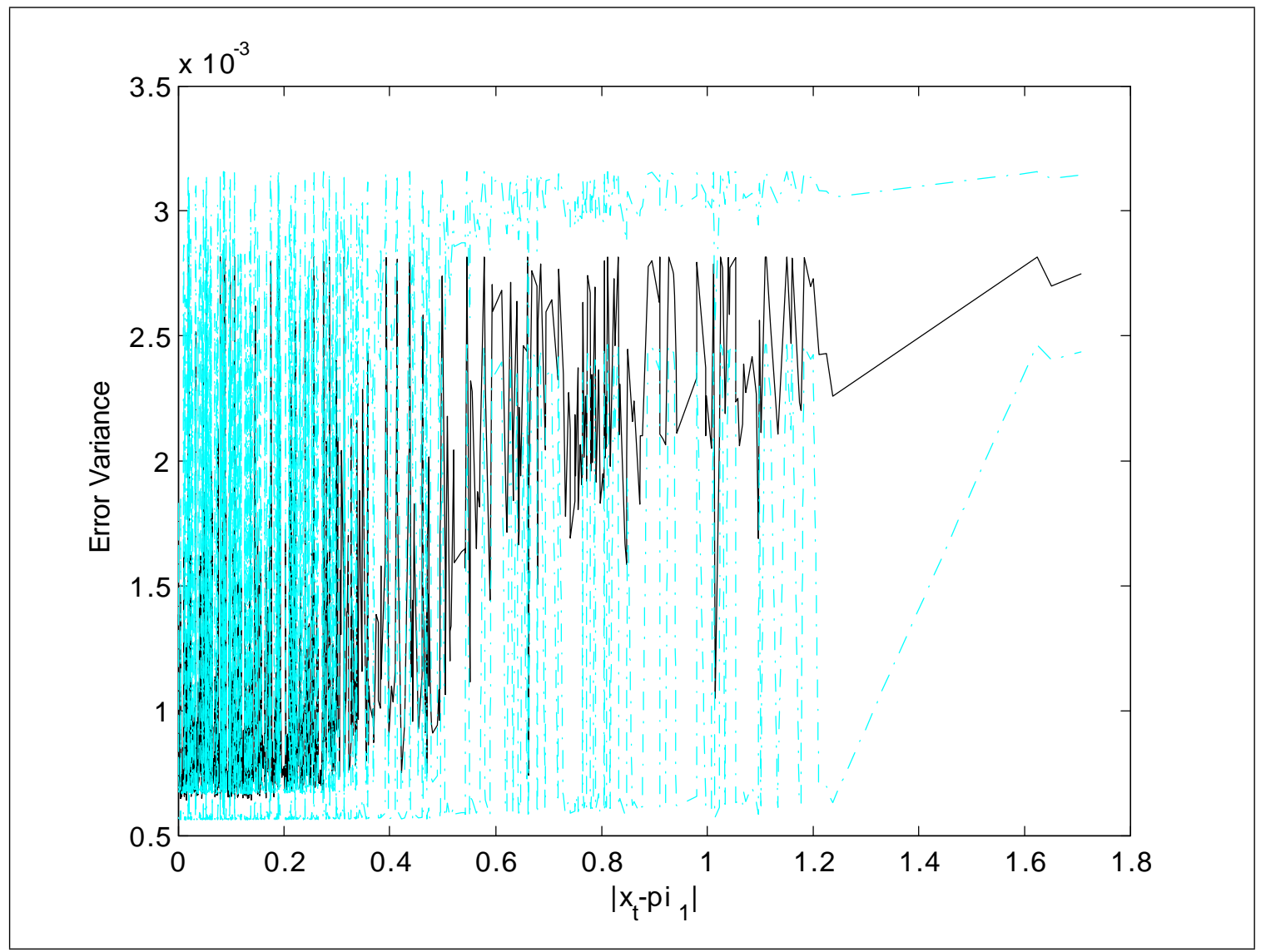

Figure A4: US Error Variance. Posterior mean (black line) and 16th-84th percentiles (blue lines) 